\title{
De los Albornoz a los Mendoza: la transmisión del estado señorial del Infantado de Huete en la Baja Edad Media
}

\section{From the Albornoz to the Mendoza: The Transmission of the Seigniorial Estate of the Infantado de Huete in the Late Middle Ages}

\author{
Pablo MARTÍN PRIETO \\ Universidad Complutense. Madrid \\ pablomartinprieto@ghis.ucm.es
}

\section{RESUMEN}

La transmisión del señorío de las llamadas villas del Infantado de Huete a lo largo de los siglos XIV y Xv da lugar a un proceso complejo pero coherente que pone en relación a algunos de los más destacados linajes y miembros de la nobleza castellana de la época. Después de haber asignado este señorío al marqués de Villena Alfonso de Aragón, el nuevo poder de la dinastía Trastámara hubo de supervisar su transmisión a los Albornoz; décadas más tarde, algunas relaciones de parentesco determinaron que este estado señorial pasara a las manos del condestable Álvaro de Luna y, tras mantenerse por algún tiempo en manos de sus descendientes, se integró, por voluntad de Enrique IV, en el patrimonio familiar de los Mendozas, a cuyo título principal acabará dando nombre.

Palabras clave: Nobleza. Aristocracia. Castilla. Baja Edad Media. Albornoz. Luna. Mendoza. Infantado

\begin{abstract}
The transmission of the estate of the so-called Infantado de Huete in the Late Middle Ages involves a complex, yet coherent, process concerning some of the Castilian aristocracy's most prominent lineages and personages at the time. After having granted this estate to the marquis of Villena, Alfonso de Aragón, the new ruling power of the Trastámara monarchs was led to approve its transmission to the Albornoz family; some decades later, on account of crucial family relations, the estate was transferred into the hands of the constable Álvaro de Luna, and after keeping within the latter's line for some time, eventually merged with the estate of the Mendoza family, whose principle title would be taken from this very estate.
\end{abstract}

Keywords: Nobility. Aristocracy. Castile. Late Middle Ages. Albornoz. Luna. Mendoza. Infantado

Sumario: Introducción. Origen y evolución del estado señorial del Infantado de Huete. La concesión del Infantado de Huete a Alfonso de Aragón, marqués de Villena. La tierra del Infantado en manos de los Albornoz. El engarce familiar del Infantado con los Luna. El Infantado de Huete en manos de los Luna (1440-1470) y la transmisión del señorío a los Mendoza. De los Luna a los Mendoza. Conclusiones 


\section{INTRODUCCIÓN}

En la tierra del llamado Infantado de Huete se halla una de las claves del entronque familiar y patrimonial del linaje conquense de los Albornoz en los de Luna y Mendoza. Precisamente es la posesión por los Mendoza del señorío sobre las villas de este Infantado la que, en los albores de la Modernidad, dará nombre al título principal de dicha familia. Seguir el proceso de la transmisión patrimonial del señorío del Infantado durante la época Trastámara aporta un ingrediente interesante a la mejor comprensión de las relaciones entre las familias citadas, a las que por añadidura pertenecieron, como es bien sabido, algunos personajes de notorio relieve público en el periodo de referencia, circunstancia esta última que parece agregar un punto de interés adicional a este estudio.

\section{ORIGEN Y EVOLUCIÓN DEL ESTADO SEÑORIAL DEL INFANTADO DE HUETE}

La población alcarreña de Alcocer se erige desde mediados del siglo XIII en centro de un señorío llamado a identificarse con la comarca que aún se denomina de la Hoya del Infantado, por la memoria de su vinculación histórica con la rama de la descendencia de Alfonso X de Castilla que arranca en su hija natural Beatriz, fruto de la cohabitación del rey Sabio con quien por un tiempo fuera su favorita, Mayor Guillén de Guzmán. Cuando Alfonso X, luego de obtener descendencia legítima de su esposa Violante de Aragón, sintió la necesidad de ofrecer a su antigua amante una salida honorable, creó para ella en 1255 un señorío de tamaño medio en torno a Alcocer, hasta entonces una aldea de Huete, donde Mayor se estableció y se ocupó principalmente en fundar, con la colaboración del rey, un monasterio de clarisas. Por su parte, sirviendo a los fines de la política del rey Sabio, Beatriz casó con Alfonso III de Portugal, y siendo reina del vecino reino heredó y retuvo el señorío creado para su madre. La transmisión del mismo se mantuvo durante seis décadas en el seno de la familia de su primera titular, hasta que la nieta de ésta, Blanca, infanta de Portugal, luego de ser nombrada señora del real monasterio de las Huelgas de Burgos, decidió deshacerse, mediante venta, del señorío formado en torno a Alcocer. La venta casi simultánea del mismo señorío a dos señores enfrentados, don Juan Manuel y el infante Pedro de Castilla, complicó su destino durante las décadas centrales del siglo $\mathrm{XIV}^{2}$. El ascenso al trono de la nueva dinastía regia de los Trastámara, emparentada al mismo tiempo con la familia manuelina y con el linaje de los Guzmán, determina un

\footnotetext{
${ }^{1}$ Abreviaturas: AHN: Archivo Histórico Nacional, Madrid. AGS: Archivo General de Simancas. RAH: Real Academia de la Historia, Madrid.

${ }^{2}$ El proceso que acabamos de resumir puede seguirse más por extenso en: Martín Prieto, Pablo: "Origen, evolución y destino del señorío creado para la descendencia de Alfonso X de Castilla y Mayor Guillén de Guzmán (1255-1312)", Temas Medievales (Buenos Aires) 11 (2002-2003) 219-240; "La fundación del monasterio de Santa Clara de Alcocer (1252-1260)", Hispania Sacra (Madrid) vol. LVII n 115 (enero-junio 2005) 227-241; El monasterio de Santa Clara de Alcocer en la Edad Media, Guadalajara, 2005.
} 
nuevo momento de interés de la corona por los destinos del señorío que nos ocupa ${ }^{3}$, cuya suerte será reorientada por decisión regia en el comienzo de esta nueva época histórica; como veremos, el proceso que así se pone en marcha acabará llevando al frente del Infantado de Huete a los Albornoz, a los Luna y a los Mendoza.

\section{LA CONCESIÓN DEL INFANTADO DE HUETE A ALFONSO DE ARAGÓN, MARQUÉS DE VILLENA}

Durante la guerra civil que enfrentó al rey Pedro con su medio hermano Enrique de Trastámara por el trono castellano, uno de los principales nobles que apoyaron el partido de este último fue don Alfonso de Aragón, conde de Denia y de Ribagorza, hijo del infante Pedro de Aragón, y nieto del rey Jaime II de Aragón. Como primo de Juana Despina, la viuda de don Fernando Manuel, hijo de don Juan Manuel, no era extraño que entretuviera aspiraciones sobre la llamada "tierra de don Juan Manuel", esto es, sobre el conjunto de villas y lugares que en el pasado habían formado parte del patrimonio del linaje manuelino ${ }^{4}$.

Recién proclamado rey, Enrique de Trastámara otorgó en 1366 a don Alfonso de Aragón el título de marqués de Villenas ${ }^{5}$ entendiendo reunir así bajo su señorío el conjunto de los lugares que habían sido de don Juan Manuel y de sus herederos. La merced fue confirmada solemnemente en las Cortes celebradas en Burgos en febrero de 1367, y en ella se incluyeron todos los lugares en el Infantado de Huete cuya compra trató don Juan Manuel con la infanta Blanca de Portugal ${ }^{6}$. Sin embargo, la situación de guerra impidió de momento al nuevo marqués de Villena tomar posesión efectiva de su señorío sobre la tierra del Infantado.

\section{LA TIERRA DEL INFANTADO EN MANOS DE LOS ALBORNOZ}

Hecho preso en la de Nájera, en abril de 1367, Alfonso de Aragón hubo de afrontar un largo cautiverio, en el curso del cual decidió desprenderse de algunos lugares de los recién adquiridos por concesión regia, con el objeto de poder pagar el alto rescate exigido para su puesta en libertad. Así, entró en negociación con la familia de los Albornoz, interesada en adquirir las llamadas villas del Infantado.

La fortuna de esta familia emergente, cuyo origen se ha vinculado con una rama segundona de uno de los mejores linajes de la nobleza vieja de Castilla, la casa de $\mathrm{Aza}^{7}$, llevaba algún tiempo incardinada en las tierras del obispado de Cuenca. En

\footnotetext{
${ }^{3}$ Martín Prieto, Pablo: "Sobre la promoción regia de la orden franciscana en la Corona de Castilla durante el primer reinado Trastámara”, Hispania Sacra, vol. LIX, no. 119 (enero-junio 2007) 51-83.

${ }^{4}$ Pretel Marín, Aurelio, Rodríguez Llopis, Miguel: El señorío de Villena en el siglo XIV, Albacete, 1998, p. 138.

${ }^{5}$ López de Ayala, Pero: Cronica del rey don Pedro, año XVII, capítulo VII.

${ }^{6}$ ARValencia, Maestre racional, 9602, fols. 108-110. Cit. Pretel-Rodríguez Llopis, El señorío de Villena, p. 145.

7 Moxó Ortiz de Villajos, Salvador: "Los Albornoz. La elevación de un linaje y su expansión dominical en el siglo XIV", en El Cardenal Albornoz y el Colegio de España, Studia Albornotiana t. XII, Bolonia, 1970, pp. 1-64 [5].
} 
efecto, Gómez García de Aza, segundón de García García de Aza, retuvo un importante papel al servicio de Alfonso VIII; como señor de Ayllón y tenente de Roa, participó verosímilmente en la toma de Cuenca en 1177, y en 1178 fue nombrado alférez. En el repartimiento de Huete obtuvo la aldea de Albornoz, origen del apellido principal del linaje, considerado el más antiguo de la nobleza conquense ${ }^{8}$. García Álvarez de Albornoz, padre del cardenal don Gil, aparece en la Crónica de Alfonso XI caracterizado como infanzón y casó con Teresa de Luna, dama perteneciente a ese importante linaje aragonés cuyos intereses lindaban con el límite oriental de Castilla. A partir de este momento, tanto la influencia política de los Albornoz en el patriciado urbano conquense como su implantación territorial en el obispado de Cuenca, especialmente al norte de la actual provincia homónima, pueden entenderse consolidados?.

El matrimonio de García Álvarez con Teresa de Luna fue origen de la mayor gloria y prosperidad que le cupo alcanzar a este linaje. Jimeno de Luna, hermano de Teresa, obispo de Zaragoza, luego arzobispo de Tarragona y finalmente de Toledo por permuta con el infante Juan de Aragón, transmitió esta última dignidad arzobispal a su sobrino Gil, hijo menor de García Álvarez. El ascenso al cardenalato de este Gil favoreció el encumbramiento definitivo del linaje de los Albornoz hasta las posiciones más elevadas dentro de la nobleza castellana. Álvar García, el hermano mayor del cardenal y primogénito del linaje, retuvo numerosas villas de señorío bajo el reinado de Alfonso XI y fue elevado a la dignidad de copero mayor bajo el rey Pedro, quien usó de sus servicios como embajador para traer a Castilla a su futura esposa Blanca de Borbón. Sin embargo, el servicio de este Álvar García a la descendencia habida por Alfonso XI en su favorita Leonor de Guzmán (Sancho, hijo de éstos, se crió en casa de Álvar García) motivó el alejamiento progresivo respecto del nuevo monarca castellano. Salvador de Moxó explicó claramente las causas y los tiempos de esta desafección, que culminó con el exilio de los principales miembros del linaje, fieles a los Trastámara, en la vertebración y consolidación de cuyo partido rebelde les cupo cierto protagonismo ${ }^{10}$, pues tanto Álvar García, el primogénito del linaje, como Fernán Gómez, el segundo, acompañarían al pretendiente Trastámara y a su consorte Juana Manuel en sus incursiones en tierra castellana para apropiarse del trono.

Fue así como Álvar García participó del lado de Enrique el Bastardo en la batalla de Nájera, al término de la cual compartió por un tiempo el destino del conde de Denia, esto es, el cautiverio, del que empero pudo sacarlo pronto su hermano menor el cardenal, gracias al pago de un pingüe rescate ${ }^{11}$. La fortuna del linaje quedó sellada por el ascenso de Enrique de Trastámara al trono castellano: la confirmación de sus antiguos lugares de señorío fue entonces complementada con generosas donaciones enriqueñas, como las de Utiel y Moya ${ }^{12}$. Es en este momento de satisfacción de las expectativas de expansión territorial del linaje, cuando la familia se embarca en la compra de las villas del Infantado de Huete, operación ambiciosa emprendida, como

\footnotetext{
${ }^{8}$ Moxó, "Los Albornoz", p. 8.

${ }^{9}$ Moxó, "Los Albornoz", p. 15.

${ }^{10}$ Moxó, "Los Albornoz", pp. 21-22.

${ }_{11}$ Moxó, "Los Albornoz", p. 23.

12 Moxó, "Los Albornoz", p. 25.
} 
hemos señalado, aprovechando la situación de necesidad que atravesaba el marqués de Villena y conde de Denia, cuyo cautiverio se prolongaba ya más de lo deseable.

Fue Álvar García de Albornoz quien gestionó la operación en nombre de su hijo primogénito micer Gómez García de Albornoz, ocupado por entonces en Italia, quien por estar casado con Constanza Manuel, llamada a veces Constanza de Villena, la última hija de Sancho Manuel, bastardo de don Juan Manuel, podía alegar intereses familiares, e incluso eventuales derechos, para la adquisición de los antiguos lugares manuelinos13. Del interés que una compra tal tenía para el referido micer Gómez da idea el hecho de que como heredero principal del cardenal don Gil contara ya, desde el fallecimiento de su tío, con el señorío de algunos lugares propios del linaje en tierras de Cuenca y Huete ${ }^{14}$. La adquisición de las villas del Infantado adquiere así una importante significación para los Albornoz: de una parte, satisface una antigua reivindicación heredada del elemento del linaje manuelino incorporado a los intereses de la familia albornocina, encarnado en la mencionada Constanza Manuel; de otra, permite ampliar y complementar la extensión territorial del solar familiar en la tierra de Huete, uno de sus ámbitos "naturales" de expansión.

El proceso necesario para materializar la operación fue largo y complejo. El 26 de marzo de 1371, micer Gómez García de Albornoz, primogénito del linaje, heredero principal de su tío el cardenal y beneficiario de la compra, desde Italia, otorgó su poder a sus procuradores, su padre Álvar García, Martín Fernández de Soria, deán de la iglesia de Cuenca, Álvar Martínez, arcediano de Huete, y Juan Fernández del Olmeda, para que en su nombre concertaran la compra con don Alfonso de Aragón ${ }^{15}$. El 5 de abril del mismo año, Alfonso de Aragón concedió a su vez plenos poderes a su tesorero, el catalán en Per de Rioles, para que en su nombre pudiera concluir la operación ${ }^{16}$. El 26 de mayo del mismo año, en Sevilla, Enrique II autorizó expresamente al marqués de Villena para que pudiera vender sus villas de Alcocer, Salmerón y Valdeolivas a micer Gómez de Albornoz, con el declarado objeto de pagar el rescate que debía al príncipe de Gales ${ }^{17}$. Para mayor seguridad y firmeza de la cesión, en el mismo mes de mayo (el día 27) la esposa de Alfonso de Aragón, la marquesa de Villena doña Violante, renunció a cualquier derecho que le cupiera retener o reclamar sobre los bienes que su esposo se disponía a vender ${ }^{18}$. La venta se celebró en la

${ }^{13}$ Pretel-Rodríguez, El señorio de Villena, p. 155.

${ }^{14}$ Cfr., al respecto, la manda $\mathrm{n}^{\circ} 40$ del testamento del cardenal: Beneyto Pérez, Juan: El cardenal Albornoz. Canciller de Castilla y Caudillo de Italia, Madrid, 1950, p. 343.

15 1371, marzo 26. Gómez García de Albornoz da poder a sus procuradores, entre ellos su padre, para comprar en su nombre cualesquiera bienes, especialmente las villas del Infantado. Inserto en AHN, Osuna, legajo 1730-4.

${ }^{16}$ 1371, abril 5. Alfonso de Aragón concede poder a sus procuradores para vender en su nombre cualesquiera lugares de los que tenía en Castilla y León. Inserto en AHN, Osuna, leg. 1730-4.

17 1371, mayo 26, Sevilla. Enrique II da licencia a Alfonso de Aragón, marqués de Villena, para vender a Gómez García de Albornoz sus villas de Alcocer, Salmerón y Valdeolivas. Incluye el albalá del 27 de mayo. Inserto en AHN, Osuna, leg. 1730 - 4; traslados en los legajos 1724-9(2) y 1724-9(3), de la misma sección; copia también en RAH, Col. Salazar, M-9, fols. 307v-308 (no. de inventario: 47609).

18 1371, mayo 27, Benamitre. Violante, marquesa de Villena, renuncia a cuantos derechos sobre las villas del Infantado pudieran eventualmente corresponderle como consorte de Alfonso de Aragón, marqués de Villena. Inserto en AHN, Osuna, leg. 1730-4. 
catedral de Cuenca, el 13 de junio del mismo año; en ella, se hacía expresa mención del señorío alto y bajo, con plena jurisdicción, mero y mixto imperio ${ }^{19}$. El monto total de la operación ascendió a 30.000 florines de oro de Aragón, esto es, según cálculos de Moxó, unos 690.000 maravedíes castellanos ${ }^{20}$, una cifra importante a todas luces. El pago fue realizado con cargo a los dineros que el cardenal don Gil le había dejado a micer Gómez ${ }^{21}$. La operación fue nuevamente ratificada por el mismo marqués de Villena el 13 de agosto $^{22}$, y recibió por segunda vez la aprobación de la corona el 22 de septiembre, en las Cortes de Toro ${ }^{23}$.

La intervención al respecto de la corona reviste especial importancia en este punto: el apoyo a la operación que la reina Juana Manuel podía aportar a la sanción de esta transmisión del señorío de Alcocer y otros de los lugares que habían sido de don Juan Manuel, es sin duda un elemento interesante; su esposo, Enrique II, asumió la jefatura informal de la casa manuelina, y como tal, primero acordó la concesión del marquesado de Villena al conde de Denia, y más tarde aprobó y favoreció la transmisión de esos derechos señoriales a la familia de los Albornoz, emparentada a su vez con la misma rama manuelina (estando micer Gómez García de Albornoz casado con Constanza Manuel o de Villena, como queda dicho).

El nuevo señor de las villas del Infantado, micer Gómez García de Albornoz, falleció en 1380 en Italia y se hizo enterrar en la iglesia conventual de las clarisas de Alcocer ${ }^{24}$. Su heredero Juan de Albornoz, que alcanzó la dignidad de copero mayor de Juan I, heredó en 1380 el mayorazgo paterno, y en 1385, por extinción de su línea, el de su tío, el hermano menor de micer Gómez, Álvar García llamado el Mozo, llegando así a reunir en su persona el patrimonio todo de la familia, incluyendo cuanto fue de su abuelo Álvar García llamado el Viejo ${ }^{25}$.

19 1371, junio 13, Cuenca. Don Alfonso de Aragón vende Alcocer, Salmerón y Valdeolivas a Álvar García de Albornoz y a su hijo Gómez García de Albornoz. AHN, Osuna, leg. 1730-4. Es traslado solicitado por Álvaro de Luna en 1438.

${ }^{20}$ Moxó, "Los Albornoz", pp. 33-34.

${ }^{21}$ 1371, mayo 11, Perpiñán. En Per de Rioles, procurador de Alfonso de Aragón, se obliga a pagar 30.000 florines de oro de Aragón a Álvar García y Gómez de Albornoz, especificando que la operación se verificará en Perpiñán, el 31 de julio del mismo año. AHN, Osuna, leg. 1724-9(4). 1371, septiembre 8, Barcelona. En Per de Rioles, en nombre de Alfonso de Aragón, hace efectivo el pago de los 30.000 florines de oro de Aragón sumando diversas cantidades facilitadas por varias sociedades comerciales europeas. AHN, Osuna, leg. 1724-9(5). Ambos son traslados solicitados por Álvaro de Luna en 1438.

${ }^{22}$ AHN, Osuna, leg. 1730-5: Moxó, “Los Albornoz”, pp. 55-58. Copia en: RAH, Col. Salazar, M-5, fol. 278 (no. de inventario: 46137).

${ }^{23}$ 1371, septiembre 22, Toro. Enrique II confirma a Gómez García de Albornoz la compra de Alcocer, Salmerón y Valdeolivas efectuada a Alfonso de Aragón, marqués de Villena. AHN, Osuna, carpeta 173, no. 12; inserto en leg. 1724-9(3) y leg. 1722-1(2). Traslados del siglo XVIII en Osuna, legajos 1724-9(2) y 1724-3(2); hay copia en RAH, Col. Salazar, M-9, fols. 308v-309 (no. de inventario: 47610); cfr. también, Cortes de León y de Castilla, RAH, t. II, p. 180; y PreTEL-RodríGuez, El señorio de Villena, p. 155.

${ }^{24}$ En un inventario no fechado de las reliquias que trajo de Italia y depositó en la iglesia parroquial de Alcocer consta que Gómez García "esta sepultado en el monasterio de Sancta Clara de la dicha su villa": RAH, Col. Salazar, N-35, fol. 174 (no. de inventario: 61860).

${ }^{25}$ Moxó, "Los Albornoz", p. 42. 
Este Juan de Albornoz estaba casado con Constanza de Castilla, hija del bastardo Tello, hermano de Enrique II y señor de Vizcaya. Juan de Albornoz falleció en 1389 sin heredero varón, dejando una hija de corta edad, María de Albornoz, y a su viuda Constanza de Castilla encinta de otra, Beatriz. De este modo quedó truncada la transmisión por recta línea de varón del linaje albornocino. Siguiendo las previsiones al respecto de Juan de Albornoz, que le conferían el usufructo vitalicio de parte de su herencia26, fue la abuela, Constanza Manuel o de Villena, viuda de micer Gómez García de Albornoz, quien se hizo cargo de las villas del Infantado durante la menor edad de la heredera del linaje, María de $\mathrm{Albornoz}^{27}$. Ésta casó en 1401 con don Enrique de Aragón, llamado de Villena, nieto de don Alfonso de Aragón, conde de Ribagorda y Denia, de cuyas manos habían comprado los Albornoz las mismas villas del Infantado. Pareciera así por un momento que la extinción de la descendencia masculina del linaje albornocino iba a desembocar en una suerte de restauración del señorío de Villena en la línea aragonesa, retomando las primeras previsiones que el fundador de la dinastía Trastámara había adoptado al respecto en 1366.

En efecto, don Enrique llamado de Villena era hijo póstumo de don Pedro de Aragón, hijo del referido marqués de Villena, Alfonso de Aragón. Pedro de Aragón, hijo segundo del marqués de Villena, había casado en 1378 con Juana de Castilla, hija bastarda de Enrique II, y falleció en la de Aljubarrota dejando a su único heredero Enrique, de muy corta edad. Casada en segundas nupcias con el infante Dionís de Portugal, Juana de Castilla promovió un pleito reclamando la devolución de la dote que había aportado a su anterior matrimonio, conforme a las capitulaciones que en su día se habían concertado, alegando que se había incumplido la promesa entonces hecha de casarla con Alfonso, hijo primogénito del marqués de Villena y conde de Denia. Este pleito lo resolvió en 1394 Enrique III, considerando el marquesado de Villena como justa equivalencia por la dote impagada: en consecuencia, desde esta fecha, se despojó del marquesado de Villena al heredero Enrique ${ }^{28}$; de la posible conciencia que en su época quedó de este despojo como un hecho injusto, podría ser indicio el hecho de que en adelante siempre se lo haya llamado Enrique "de Villena". La concesión del condado de Cangas de Tineo y la concertación de su matrimonio con la heredera del linaje albornocino, María de Albornoz, en 1401, fue decisión de Enrique III, como una suerte de compensación por la pérdida del marquesado de Villena. Es voz común de la época que María de Albornoz fue amante de Enrique III. Por esta u otras razones, parece que su matrimonio con Enrique de Villena distó de ser un éxito. Cuando en 1404 vacó el maestrazgo de la orden militar de Calatrava, Enrique de Villena se embarcó en una arriesgada (y a la postre frustrada) operación

26 "Donna Costança de Villena tovo las dichas villas, que las tovo asi commo usofrutuaria dellas, por que le fueron mandadas por el dicho don Iohan de Albornoz, su fijo, por su vida, para su mantenimiento": AHN, Osuna, carpeta 174, no. 9.

${ }^{27}$ Ignoramos a partir de este momento el destino de Constanza de Castilla, madre de María de Albornoz: ¿falleció quizás en el parto de Beatriz, hija póstuma de Juan de Albornoz? Lo cierto es que durante la menor edad de María de Albornoz, es su abuela Constanza Manuel, llamada de Villena, quien figurará al frente del señorío del Infantado de Huete, como veremos, y no Constanza de Castilla, su madre, de la que nada sabemos en adelante.

${ }^{28}$ Cotarelo Mori, Emilio: Don Enrique de Villena: su vida y obras, Madrid, 1896, p. 23. 
destinada a ocupar ese puesto, para lo cual se decidió la renuncia del condado de Cangas y la anulación de su matrimonio, disuelto sin heredero legítimo. En consecuencia, puede afirmarse que a los efectos de nuestra investigación la figura de Enrique de Villena es punto menos que irrelevante, puesto que nunca alcanzó participación real ni directa en los asuntos del señorío del Infantado de Huete, que en todo momento se mantuvieron gestionados por su enérgica consorte María de Albornoz.

Esta dama, "último eslabón del linaje" albornocino"29, retuvo el señorío nominalmente desde la muerte de su padre Juan de Albornoz el 28 de octubre de $1389^{30}$ hasta su propia muerte, acaecida el 17 de abril de $1440^{31}$. Durante los primeros de esos años fue su abuela Constanza Manuel, llamada de Villena, viuda de micer Gómez García de Albornoz, quien se ocupó de los asuntos del señorío. Heredera de las propiedades acumuladas por su marido durante su etapa al frente del señorío, Constanza de Villena poseía abundantes intereses en bienes raíces en la villa de Alcocer, la más importante de las del Infantado de Huete, como se atestigua por la importante operación de permuta que Constanza concertó en 1402 con un propietario particular: a cambio de una casa de molinos junto al puente sobre el río Guadiela, Constanza cedió una extensa lista de propiedades rústicas, viñas, tierras de pan y olivares, en lo que constituye la más extensa relación de aprovechamientos agrarios que se hallará en la documentación local de la época ${ }^{32}$. Cabría preguntarse en este punto por el origen de esta copiosa nómina de propiedades rústicas en Alcocer: aunque la documentación no es explícita al respecto, es posible que algunas de estas propiedades hubieran sido adquiridas por Constanza en el tiempo que ejerció la función señorial en nombre de su nieta, o bien que formaran parte de la herencia dejada por su esposo. Este último caso daría lugar a un interrogante sobre la procedencia de los mismos bienes en manos de micer Gómez García de Albornoz: cabe suponer que formaran parte de la herencia familiar transmitida en un primer lote por su tío el cardenal y en un segundo momento por su padre Álvar García; asimismo podría tratarse de bienes adquiridos por el mismo micer Gómez García durante los años que estuvo al frente del señorío. Por supuesto, las anteriores suposiciones no se excluyen entre sí, y la cuestión queda por el momento en suspenso, a la espera del hallazgo de documentación que pueda arrojar nueva luz sobre el asunto.

La intervención de Constanza al frente de los asuntos del señorío rebasa con mucho los años de la menor edad de su nieta María de Albornoz, en cuyo nombre la ejercía. Cabe suponer al respecto que durante una primera etapa de su vida, especialmente mientras moró en el convento de Santa Clara de Guadalajara ${ }^{33}$, María

\footnotetext{
${ }^{29}$ Moxó, "Los Albornoz", p. 45.

${ }^{30}$ Moxó, "Los Albornoz", p. 42.

${ }^{31}$ Moxó, “Los Albornoz”, p. 46, nota 139, citando la Crónica del Halconero (ed. Carriazo, Madrid, 1946, p. 336).

32 1402, septiembre 16, Alcocer. Juan Martínez cambia su molino del Guadiela (consta de tres ruedas, dos de la capellanía de su hermana Catalina Martínez y la otra suya) a Constanza de Villena, por una extensa serie de tierras dispersas en el término de Alcocer. Juan, obispo de Cuenca, como más alto custodio de los bienes de la mencionada capellanía, aprueba y confirma el trueque. AHN, Clero, carpeta 568, no. 9 .

${ }^{33}$ Layna Serrano, Francisco: Los conventos antiguos de Guadalajara, Madrid, 1943, pp. 86-89.
} 
de Albornoz confirmó a su abuela Constanza la administración como usufructuaria vitalicia del señorío de las villas del Infantado, tal y como se la había concedido y reconocido su padre Juan de Albornoz. De esta manera, es Constanza quien figura como señora de facto de Alcocer cuando en 1419 compra, valiéndose de interpuesta persona, una propiedad rústica puesta en pública almoneda por los testamentarios de Teresa Díaz, viuda del contador de Enrique III Sancho Fernández de Cifuentes, notable del lugar ${ }^{34}$. En una primera versión de su testamento, esta Constanza Manuel o de Villena vinculó las rentas de sus molinos del puente del Guadiela, cuya adquisición ya hemos referido en 1402, a la fundación y dotación de tres capellanías en la iglesia parroquial de Alcocer, por las almas de sus difuntos esposo e hijo; sin embargo, a través de un codicilo modificó en último término esta su postrera voluntad y donó los mismos molinos al monasterio de clarisas de la misma villa, por razón de limosna y con el ruego de que la comunidad incluyera a los tres en sus oraciones ${ }^{35}$. En esta significativa modificación entrevemos con cierta claridad el grado de vinculación y proximidad que Constanza Manuel había establecido, como señora de Alcocer, con la comunidad clarisa de la villa, en cuya iglesia conventual se hizo enterrar ${ }^{36}$.

\section{EL ENGARCE FAMILIAR DEL INFANTADO CON LOS LUNA}

En 1429 ya había fallecido la abuela Constanza Manuel, como consta por la toma de posesión de los referidos molinos, que a su muerte ejecutaron los representantes de la comunidad clarisa de Alcocer, siguiendo sus previsiones testamentarias ${ }^{37}$. A partir de este momento María de Albornoz se hace personalmente con las riendas del señorío del Infantado. Tomando conciencia del hecho cierto de que carecía de heredero legítimo, María de Albornoz acordó ceder su herencia a don Álvaro de Luna, condestable de Castilla y hombre fuerte del reino. Esta decisión no es sorprendente si tenemos en cuenta las previsiones que al respecto adoptara en vida su difunto padre, Juan de Albornoz. En efecto, la herencia de Juan de Albornoz se repartió entre sus dos hijas, María de Albornoz y Beatriz, a quien aquél no llegó a conocer. La línea de Beatriz, casada con don Diego Hurtado de Mendoza, primer señor de Cañete, resultó

34 1419, abril 12, Alcocer. Lope García y Gil Martínez, testamentarios de Teresa Díaz, viuda de Sancho Fernández de Cifuentes, venden en almoneda pública dos terceras partes de la viña de la senda del Galletero, propiedad de la fallecida, a Constanza de Villena, señora de Alcocer, para hacer frente a las mandas del testamento. AHN, Clero, carpeta 568, no. 13.

35 1428, diciembre 17, y 1429, febrero 13, Alcocer. Codicilo del testamento de Constanza de Villena, viuda de micer Gómez de Albornoz, rectificando una manda de su testamento, para conceder a su muerte unos molinos en el Guadiela al monasterio de Santa Clara de Alcocer; y la toma de posesión de estos molinos por parte de fray Luis de Alcocer, procurador del monasterio. AHN, Clero, carpeta 569, no. 2.

${ }^{36} \mathrm{Su}$ enterramiento al lado del altar mayor de la nueva iglesia conventual intramuros consta en la tradición oral de la comunidad, recogida en el llamado Quaderno redactado en 1656 por fray Gregorio de Heredia, vicario del monasterio clariso de Alcocer, y conocido a través de una copia de 1720 consultada por Juan Catalina GARCíA LóPEZ, de cuya generosa recensión dependemos para el conocimiento de este documento: Biblioteca de escritores de la provincia de Guadalajara y bibliografía de la misma hasta el siglo XIX, Madrid, 1899, pp. 596-599 [598].

37 AHN, Clero, carpeta 569, no. 2 (vid. supra, en nota 34). 
tempranamente extinta ${ }^{38}$, de manera que tan sólo de la línea de María de Albornoz dependía el futuro del patrimonio familiar albornocino. En una de las cláusulas del testamento de Juan de Albornoz se preveía que el mayorazgo familiar, faltando descendencia legítima de la rama principal, la cual tan sólo María de Albornoz se hallaba en disposición de concebir, debería pasar a la línea de los Luna ${ }^{39}$. A este respecto debemos tener en cuenta el parentesco que unía a ambas familias desde el momento en que Teresa de Albornoz, hija mayor de Álvar García de Albornoz el Viejo, casara con el segundo Juan Martínez de Luna ${ }^{40}$.

Fue así siguiendo las previsiones al respecto adoptadas por su difunto padre Juan de Albornoz que María de Albornoz tomó en 1432 la decisión de nombrar su heredero universal a don Álvaro de Luna, condestable de Castilla, cabeza del linaje emparentado de los Luna, decisión materializada en una donación inter vivos con reserva del usufructo sobre el señorío de sus villas y lugares, que María siguió ejerciendo hasta su muerte ${ }^{41}$. Esta donación, en sus mismos términos, fue confirmada, en vida de María de Albornoz, por el rey Juan II, en dos ocasiones, en 1432 y 1438, a instancias del precavido condestable ${ }^{42}$.

Aun después de decidir el destino del patrimonio familiar del que era depositaria donando sus villas y lugares al condestable, María de Albornoz siguió al frente del señorío, ejerciendo sus funciones de manera activa. De esta manera la encontramos cuando en 1433 alcanzó con el concejo de la villa de Alcocer un acuerdo para cederle en bloque el disfrute de las rentas señoriales de martiniega, pedido, portazgo, escribanía y almotazanería, que hasta entonces retenía, a cambio de un pago anual de 30.000 maravedíes que el concejo debía satisfacer en tres plazos iguales a lo largo del año ${ }^{43}$. En un pleito de 1438, María de Albornoz ejercía como señora de las villas del Infantado, las cuales reclamaron su derecho acostumbrado de aprovecharse de

${ }^{38}$ Moxó, "Los Albornoz", p. 45.

${ }^{39}$ AHN, Osuna, leg. 2213-13.

${ }^{40}$ Moxó, "Los Albornoz", p. 37.

41 1432, marzo 15, Alcocer. María de Albornoz, como titular del mayorazgo instituido por su padre Juan de Albornoz, en cuyas cláusulas se estipulaba que en caso de extinción de su línea heredase el mayorazgo su primo Álvaro de Luna, dona a éste las villas de Albornoz, Beteta, Torrealba, Salmerón y Alcocer, y la casa de Ribagorda, reteniendo para sí en vida el usufructo de todo ello. AHN, Osuna, leg. 1725-1. Copia en RAH, Col. Salazar, M-10, fols. $62-64$ (no. de inventario: 47785).

42 1432, marzo 22, Valladolid. Juan II ordena al concejo de Salmerón que reciba por señor de la villa al condestable Álvaro de Luna, tras la donación del señorío efectuada en su favor por María de Albornoz. AHN, Osuna, leg. 1724-13(3). 1440, abril 23, Bonilla de la Sierra. Juan II ordena a las villas de Alcocer y Salmerón, y a otros lugares que fueron de María de Albornoz, que reciban por señor al condestable Álvaro de Luna. AHN, Osuna, leg. 1724-13(6).

${ }_{43}^{4}$ 1433, mayo 1, Alcocer. María de Albornoz, señora de Alcocer, cede al concejo de esta villa las rentas señoriales de martiniega, pedido, portazgo, escribanía y almotazanería, a cambio de un pago anual de 30.000 maravedíes en tres plazos de 10.000 maravedíes cada uno. AHN, Osuna, leg. 172415(1): traslado de 1549, febrero 5, Alcocer. Sendos traslados de 1732 en legajos 1724-15(2), 172415(3) y 1724-15(5). Traslado del traslado de 1549 en leg. 1724-15(4). En el Archivo Provincial de Guadalajara, Catastro de Ensenada, existe asimismo un traslado de 1752, septiembre 20, Alcocer. 
los pastos comunales de la ciudad vecina de Huete ${ }^{44}$ : se acredita así la intervención activa de María al frente del señorío en esa fecha, y cabe suponer que hasta su muerte, acaecida, como hemos mencionado, en 1440. Su fallecimiento en ese año supone, por extinción natural de la línea principal del linaje, el final de la vinculación, que se prolongó desde 1371 hasta 1440, de los lugares del Infantado de Huete con la familia de los Albornoz.

\section{EL INFANTADO DE HUETE EN MANOS DE LOS LUNA (1440-1470) Y LA TRANSMISIÓN DEL SEÑORÍO A LOS MENDOZA}

Es, así pues, a partir de 1440 cuando las villas y lugares del Infantado de Huete se integran efectivamente en el patrimonio señorial de don Álvaro de Luna, condestable de Castilla, pero cierto grado de intervención de este prohombre en los asuntos del señorío puede ya rastrearse desde algunos años antes de su efectiva toma de posesión del mismo, concretamente desde el momento en que María de Albornoz le cediera, reservando para sí misma el usufructo vitalicio, el señorío de estas villas en 1432.

Ya hemos hecho mención más arriba a la carencia de descendencia legítima directa para la herencia de María de Albornoz como un factor decisivo en la importante decisión que esta dama tomó en 1432. Tempranamente fallecidos tanto la hermana Beatriz como su hijo Luis Hurtado de Albornoz, a quien estaba destinada parte de la herencia de Juan de Albornoz como resultado de los acuerdos familiares previos, María de Albornoz pudo sentirse legitimada para disponer de toda la herencia como lo hizo, donándosela en vida a su primo el condestable. Sin embargo, subsistió cierta duda en cuanto a los derechos sobre cierta parte de la herencia que como heredero de su hijo fallecido podían corresponderle a Diego Hurtado de Mendoza, viudo de Beatriz. La intervención del condestable en la resolución del pleito planteado por esta cuestión está suficientemente documentada, y da idea de hasta qué punto, a partir del momento en que fue designado beneficiario de esa donación y de la herencia que llevaba aparejada, ejerció una cautelosa función tutelar sobre los asuntos de su prima María de Albornoz, defendiendo en último término sus propios derechos a percibir la integridad de la referida herencia ${ }^{45}$. Para ello fue asimismo necesario sortear un obstáculo de orden menor, como era cumplir la condición, expresada por María de Albornoz en su donación de 1432, encaminada a asegurar que el heredero de esos bienes conservara el nombre de Albornoz: a esa exigencia hizo frente el condestable con una modificación de las condiciones de su mayorazgo, previa a despejar toda salvedad que pudiera estorbar su pacífica toma de posesión de la herencia ${ }^{46}$.

${ }^{4} 1438$, octubre 16, Buendía. Sentencia en el pleito entre María de Albornoz y sus lugares de Alcocer, Salmerón, Valdeolivas y San Pedro de Palmiches de una parte, y la ciudad de Huete de la otra, por el aprovechamiento que los primeros hacían de los pastos comunales de la última. AHN, Osuna, carpeta 174 , no. 9.

${ }^{45}$ Sobre el planteamiento y resolución de este pleito que enfrentó a María de Albornoz con Diego Hurtado de Mendoza por la herencia de Beatriz de Albornoz, cfr. CALderón OrTegA, José Manuel: Álvaro de Luna: riqueza y poder en la Castilla del siglo XV, Madrid, 1998, pp. 183-185.

${ }^{46}$ Calderón Ortega, Álvaro de Luna, pp. 185-186. 
Sin embargo, esa pacífica toma de posesión fue de hecho estorbada y hubo de postponerse por algún tiempo. Fallecida como hemos visto María de Albornoz el 17 de abril de 1440, Alvaro de Luna se aprestó a dar los primeros y necesarios pasos para proceder a la toma de posesión de la herencia a la que tenía derecho en virtud de la donación otorgada por aquélla en 1432. De esta forma, en primer lugar obtuvo del rey, el 23 de abril, una providencia dirigida a los concejos de las villas del Infantado y otros lugares de María de Albornoz destinada a asegurar la recepción favorable a su razonable demanda, que todavía no se había producido, pero cabía esperar como inminente, de tomar posesión del señorío de todos ellos ${ }^{4}$. A continuación, el 27 de abril, el condestable designó a sus procuradores para que lo representaran en los actos de toma de posesión del señorío ${ }^{48}$. Sin embargo, al parecer se produjo alguna resistencia por parte de las autoridades locales, o alguna otra circunstancia que hizo necesaria la nueva intervención de Juan II, ordenando a Juan de Silva, alférez mayor del pendón real, que amparara en nombre de la corona la posesión de la herencia por parte del condestable ${ }^{49}$. La causa que hizo precisa la intervención del rey en un proceso que parecía claro y cuyo desarrollo quedó por un tiempo en suspenso no fue otra que la reivindicación del infante Enrique de Aragón, maestre de la orden de Santiago, quien alegando ciertos derechos que entendía le asistían, interpuso sus gentes de armas, irrumpiendo así en las villas del Infantado con efectivos suficientes para impedir que el condestable pudiera completar su toma de posesión sobre dichos lugares.

En efecto, como nieto de Sancho, hermano de Tello, señor de Vizcaya, de quien descendía María de Albornoz, el infante Enrique de Aragón creyó poder imponer la reivindicación de su derecho moviendo sus efectivos, y una fuerza armada formada por 400 caballeros a su servicio, asistidos por unos pocos miles de peones reclutados en la tierra de Huete, al mando de Manuel de Benavides y García de Cárdenas, ocupó Alcocer y las otras villas de Infantado en su nombre ${ }^{50}$. Para evitar el enfrentamiento armado particular entre los dos pretendientes, el rey ordenó secuestrar cautelarmente los lugares en litigio hasta que se alcanzara un acuerdo sobre su titularidad, y en nombre de la corona tomó posesión de los mismos el doctor Pedro González de Fontiveros, funcionario regio de su confianza, oidor de la audiencia real ${ }^{51}$.

La controversia tardó dos años en resolverse. Esta circunstancia puede relacionarse con la rivalidad política que durante estos años se interpuso entre el condestable

47 1440, abril 23, Bonilla de la Sierra. Juan II ordena a las villas de Alcocer y Salmerón, y a otros lugares que fueron de María de Albornoz, que reciban por señor al condestable Álvaro de Luna. AHN, Osuna, leg. 1724-13(6).

48 1440, abril 27, Escalona. El condestable Álvaro de Luna da poder a sus procuradores para que en su nombre procedan a tomar posesión de la herencia de María de Albornoz, dentro de la cual se cuentan las villas del Infantado. AHN, Osuna, leg. 1727-6(1).

49 1440, mayo 2, Tordesillas. Juan II ordena a Juan de Silva, alférez mayor del pendón real, que ampare la posesión por parte de don Álvaro de Luna de la herencia de María de Albornoz. AHN, Osuna, leg. 1724-13(7).

${ }^{50}$ Crónica del Halconero, pp. 336-337.

${ }^{51}$ Así constan acreditados su oficio y condición, por ejemplo, al confirmar como testigo la renuncia efectuada en 1442 por el infante Enrique de Aragón: cfr. AHN, Osuna, leg. 1724-2; también en leg. 1727-8(1) y en leg. 1724-13(9). 
y el maestre de Santiago. Al cabo, en octubre de 1442 el infante Enrique consintió en renunciar, sin condiciones ni contraprestación formal alguna, a todo el derecho que eventualmente pudiera haberle asistido a la propiedad de las villas del Infantado ${ }^{52}$. Esta renuncia, aprobada por el rey como supremo árbitro de la contienda ${ }^{53}$, dejó al fin expedito el camino para que Álvaro de Luna pudiera hacerse con el control del Infantado y de los restantes lugares de la herencia de María de Albornoz.

Para mayor claridad, Juan II procedió en primer lugar a ordenar a Pedro González de Fontiveros, que durante dos años había mantenido secuestrados todos esos lugares en nombre de la corona, que los entregara a Álvaro de Luna ${ }^{54}$; en segundo lugar, se ocupó, seguramente cediendo a insistente ruego del condestable, de confirmar y legitimar con el sello de la corona, una vez más, los términos en los que se efectuaba la transmisión de toda la herencia de María de Luna a las manos de don Álvaro ${ }^{55}$.

La resolución del conflicto tuvo lugar en octubre de 1442; en el mes de noviembre se procedió a la definitiva toma de posesión por parte de los representantes del condestable en cada uno de los lugares del Infantado. Valiéndose de los plenos poderes concedidos por el condestable ${ }^{56}$, su camarero Fernando de Valladolid tomó posesión en nombre suyo del señorío en Alcocer el 7 de noviembre ${ }^{57}$, el 9 del mismo mes en Valdeolivas ${ }^{58}$, el día 10 en Salmerón ${ }^{59}$, así como de las casas que fueron de María de Albornoz en Millana (día 11) ${ }^{60}$ y en Ribagorda (día 15) ${ }^{61}$. Juan de Camargo, vecino de Alcocer, representante del ya señor de la villa, procedió el 21 de noviembre a tomar posesión de la heredad sita en el término de Burbanos, dentro del alfoz de Huete $^{62}$, heredad que al parecer había formado parte del patrimonio de los Albornoz

52 1442, octubre 6, Toledo. El infante Enrique de Aragón renuncia a cuantos derechos pudiera tener sobre los bienes dejados en herencia por María de Albornoz, en beneficio de don Álvaro de Luna, condestable de Castilla. AHN, Osuna, leg. 1724-2; copia inserta en leg. 1727-8(1), y otra en leg. 172413(9).

53 1442, octubre 20, Arévalo. Carta ejecutoria de la sentencia pronunciada por Juan II en el pleito entre el condestable Álvaro de Luna y el infante Enrique de Aragón por la herencia de María de Albornoz. AHN, Osuna, leg. 1724-13(9); también en leg. 1727-14(4a).

${ }_{54} 1442$, octubre 17, Arévalo. Juan II ordena al oidor Pedro González de Fontiveros, secuestrador real de las villas del Infantado, que se las entregue al condestable Álvaro de Luna. Inserto en AHN, Osuna, leg. 1727-14(2). Hay un traslado del siglo XVIII en leg. 1724-13(8).

55 1442, octubre 30, Santa María de Nieva. Juan II avala la transmisión por herencia de todos los bienes de la difunta María de Albornoz al condestable Álvaro de Luna. AHN, Osuna, leg. 1724-3. Hay un traslado corrupto, del siglo XVIII, en el legajo 1724-13(10).

${ }^{56} 1442$, octubre 2, Arenas. Álvaro de Luna concede a su camarero Fernando de Valladolid todo su poder para que en su nombre y como procurador suyo tome posesión de las villas del Infantado y otros lugares que fueron de María de Albornoz, en tierras de Cuenca y Huete. Inserto en AHN, Osuna, leg. 1727-14(2).

57 1442, noviembre 7, Alcocer. Fernando de Valladolid, camarero del condestable don Álvaro de Luna, toma en su nombre posesión del señorío de la villa de Alcocer. AHN, Osuna, leg. 1727-14(2).

${ }^{58}$ AHN, Osuna, leg. 1727-14(3).

${ }^{59}$ AHN, Osuna, leg. 1727-14(4a).

${ }^{60}$ AHN, Osuna, leg. 1727-14(5).

${ }^{61}$ AHN, Osuna, leg. 1727-14(5a).

62 "En una tierra faça de pan levar que es en termino de Burbanos, logar e jurediçion de la çibdad de Huete"; en este documento, al nuevo señor Álvaro de Luna se lo identifica, entre otros títulos, y 
en la zona y que dependía de Alcocer como cabeza que bajo el señorío de María de Albornoz había sido de la administración de las villas del Infantado. El proceso de la toma de posesión de la herencia de María de Albornoz se culmina con la solemne prestación conjunta de pleito homenaje por parte de los representantes concejiles de las tres villas del Infantado, Alcocer, Salmerón y Valdeolivas, reunidos ante el mismo condestable Álvaro de Luna, en su castillo de Escalona ${ }^{63}$.

Así pues, aunque pudo haber figurado nominalmente como señor del Infantado de Huete desde que María de Albornoz le cediera sus derechos en 1432, no fue hasta finales de de 1442 cuando Álvaro de Luna pudo afirmarlos y comenzar a ejercerlos de manera efectiva. Por ejemplo, en el caso de Alcocer, como resultado de los capítulos acordados en el momento de la toma de posesión del señorío, el condestable retuvo como señor los mismos derechos que le habían correspondido a María de Albornoz, esto es, de una parte el cobro de ciertas rentas señoriales entre las que se puede contar la que el concejo de la villa ofrecía a su señor en equivalencia por retener el cobro y la gestión directos de martiniega, pedido, portazgo, escribanía y almotazanería, tal y como se había acordado con aquélla en 1433; de otra, la titularidad de la jurisdicción, concretada en la ostentación del señorío de la justicia, incorporado al ceremonial de la toma de posesión ${ }^{64}$. A partir de 1452, por concesión regia, a estos derechos vino a sumarse la percepción de las tercias reales ${ }^{65}$, lo que constituye un importante capítulo dentro de la renta señorial, al tiempo que un testimonio del estrechamiento de la vinculación del condestable con las villas del Infantado ${ }^{66}$.

Sin embargo, poco después de esta crucial concesión regia, la vinculación con las villas del Infantado del condestable hubo de quedar bruscamente cercenada por su caída en desgracia. Cuando Juan II ordenó prender al condestable, al objeto de neutralizar preventivamente todo intento de resistencia por parte de sus todavía numerosos y potentes partidarios, ordenó también la prisión de sus familiares y el secuestro de todos sus bienes ${ }^{67}$, entre los que evidentemente hemos de entender incluidas las villas del Infantado. Ajusticiado el condestable el 2 de junio de 1453, quedaban por reducir su viuda Juana Pimentel y su hijo Juan de Luna, sitiados en Escalona, quienes

muy significativamente, como "sennor de Albornoz e del Infantadgo". AHN, Osuna, leg. 1727-14(10).

${ }_{63} 1442$, diciembre 8. Escalona. Ferrán González y Juan González, procuradores de Alcocer, Miguel López, alcalde y Mateo Estébanez, regidor, procuradores de Valdeolivas, y Pedro Fernández y Martín Alfonso de Alcázar, procuradores de Salmerón, prestan pleito homenaje al condestable Álvaro de Luna en su castillo de Escalona, "en la sala donde su merced oye misa". AHN, Osuna, leg. 1726-4.

64 Especialmente, el procurador del condestable, durante los actos de toma de posesión, visitó la cárcel, donde se apoderó simbólicamente de las cadenas ("fue a la carçel e casa de Ferrand Sanchez d'Escamilla, teniente de alguazil, et el dicho Ferrand Sanchez dio e entrego las cadenas e prisiones que de la dicha villa tenia, e en espeçial, una cadena") e incluso libró algunos pleitos especialmente preparados para la ocasión ("fue a la audiençia desta dicha villa, onde se acostunbran librar los pleitos, e asentose en el poyo della a oyr e librar pleitos"): AHN, Osuna, leg. 1727-14(2). Sobre la función representativa de este género de actos en las tomas de posesión de la época, cfr. BECEIRo PITA, Isabel: "El escrito, la palabra y el gesto en las tomas de posesión señoriales", Studia historica. Historia medieval 12 (1994) 53-82.

${ }^{65}$ AGS, Mercedes y Privilegios, leg. 1, f. 547.

${ }^{66}$ Calderón Ortega, Álvaro de Luna, p. 188.

${ }^{67}$ Calderón Ortega, Álvaro de Luna, pp. 95-96. 
negociaron con los emisarios regios un trato destinado a asegurar su sumisión pacífica a la corona y la preservación parcial de los bienes y derechos que habían pertenecido en su vida al condestable, a cambio de la entrega de una parte substancial del tesoro que el mismo había reunido en el castillo de la referida villa de Escalona, a la que se podría considerar como cabeza de los lugares que fueron de Álvaro de Luna ${ }^{68}$.

Como parte de la negociación, a cambio de la entrega del tesoro de Escalona y de algunas villas que el condestable tuvo en vida como maestre de la orden militar de Santiago, su hijo y heredero, Juan de Luna, recibió de Juan II el señorío de buena parte de los lugares que habían sido de su padre don Álvaro, encabezados por la villa de San Esteban de Gormaz, con título condal anejo. Entre esos lugares figuraban las villas del Infantado de Huete ${ }^{69}$. La merced regia se completó poco después, entregadas ya las dos terceras partes del tesoro de Escalona y como signo del perdón regio, con la concesión de las tercias reales de las villas del Infantado (entre otros lugares), tal y como las había disfrutado en vida el condestable. El cobro de dichas tercias había sido asimismo objeto de secuestro expreso por oficiales de la corona desde el prendimiento de Álvaro de Luna ${ }^{70}$. De esta forma, luego de un breve interregno durante el cual las villas del Infantado se mantuvieron secuestradas por la corona, retornaron sin más contratiempo a manos de los Luna, anudándose así la continuidad en la transmisión de su señorío dentro de dicha familia ${ }^{71}$.

Juan de Luna, hijo del condestable y de Juana Despina, poseyó pacíficamente el señorío $\mathrm{O}^{72}$ y retuvo el cobro de las tercias reales de las villas del Infantado desde 1453 hasta su muerte, acaecida en 1459, fecha en la que el nuevo monarca, Enrique IV, acordó con la viuda del condestable y cabeza visible del linaje un estatuto de tutela para la heredera del condado de San Esteban de Gormaz y del estado señorial de Juan de Luna, su hija menor de edad Juana de Luna. En virtud de este acuerdo, Enrique IV, embarcado en la enérgica política de recuperación de las rentas y derechos de la corona que caracterizó la primera y exitosa etapa de su reinado, asumió el señorío de facto de las villas del Infantado de Huete, hasta que Juana de Luna cumpliera los doce años ${ }^{73}$.

${ }^{68}$ Calderón Ortega, Álvaro de Luna, p. 102.

${ }^{69}$ 1453, junio 30, Escalona. Juan II concede a Juan de Luna el condado de San Esteban de Gormaz y otros lugares que fueron de su padre: cfr. la notificación a la ciudad de Osma, uno de ellos, en AHN, Osuna, leg. 1735-2(1).

70 1453, julio 12, Escalona. Juan II concede al conde de San Esteban de Gormaz las tercias reales de Osma, villas del Infantado y otros lugares, tal como las disfrutó en vida su padre el condestable: cf. AHN, Osuna, leg. 1724-10(1).

${ }^{71}$ Sobre las vicisitudes de la herencia de Álvaro de Luna, véase: Franco SiLva, Alfonso: "El destino del patrimonio de don Álvaro de Luna: problemas y conflictos en la Castilla del siglo xv", Anuario de Estudios Medievales 12 (1982) 549-585.

${ }^{72}$ Consta la confirmación del condado de San Esteban de Gormaz y otros lugares concedida por Enrique IV el 2 de diciembre de 1455: cfr. García López, Juan Catalina: Relaciones topográf cas de España. Provincia de Guadalajara, con notas y aumentos, Memorial Histórico Español, t. XLI, Madrid, 1903, p. 164.

73 1459, mayo 4, San Esteban de Gormaz. Documento mencionado en García LóPEz, Relaciones topográf cas, p. 164. 


\section{DE LOS LUNA A LOS MENDOZA}

En 1460, Íñigo López de Mendoza, hijo y heredero de Diego Hurtado de Mendoza, segundo marqués de Santillana, contrajo nupcias con María de Luna, hermana de Juan de Luna ${ }^{74}$. Esta alianza entre los Mendoza y los Luna ofrecía a Enrique IV la posibilidad de asignar el señorío de las villas del Infantado a la rama de los Mendoza que nacía de dicho enlace matrimonial, como medio de recompensar la lealtad del clan mendocino, sin que por demás el Infantado de Huete perdiera su vinculación con los Luna. Para realizar este propósito era necesaria la colaboración de los titulares del señorío, esto es, de la condesa de San Esteban Juana de Luna y su marido, Diego López Pacheco, quien había sucedido a su padre Juan Pacheco, maestre de la orden militar de Santiago, en el marquesado de Villena. Contando con esta colaboración, Enrique IV tomó en 1470 la iniciativa y promovió la operación destinada a endosar las villas del Infantado al estado señorial del segundo marqués de Santillana.

Como primera providencia, Enrique IV concedió en mayo de 1470 a Juana de Luna su licencia para disponer con libertad del señorío de las villas del Infantado, facultándole de este modo para que pudiera segregarlas del mayorazgo encabezado por el condado de San Esteban de Gormaz, ya fuera para venderlas, empeñarlas o permutarlas de cualquier manera ${ }^{75}$. Un primer paso destinado sin duda a facilitar las negociaciones y la ulterior transmisión patrimonial en que éstas habrían de desembocar. Como resultado de las negociaciones entre la condesa de San Esteban, su marido el marqués de Villena y el monarca, los dos primeros acordaron ceder las villas del Infantado a éste último, esperando del monarca en equivalencia alguna contraprestación que a finales de septiembre aún no se había concretado, como consta por una carta expedida a sus vasallos de dichas villas para que recibieran por su señor a Enrique $\mathrm{IV}^{76}$. El trato se concretó y materializó de manera definitiva el 8 de octubre de 1470, fecha en que se firmó la permuta de las referidas villas del Infantado por la ciudad de Alcaraz ${ }^{77}$. En consecuencia, a partir de esa fecha la primera parte de la operación puede entenderse consumada: Enrique IV pasa a convertirse en señor de iure de las villas y lugares del Infantado de Huete, y los marqueses de Villena reciben a cambio la ciudad de Alcaraz. A este último respecto, cabe destacar en este punto la premura con que en el documento original se insertó a última hora, con otra tinta y pudiera ser que por otra mano, el nombre de esta ciudad, tantas veces cuantas debía figurar en el mismo, después de que todo el resto del diploma ya estuviera preparado, como último y crucial retoque: indicio éste inequívoco de que las negociaciones sobre el bien que la corona contaba asignar como contraprestación por las villas del Infantado quedaron abiertas hasta muy última hora, y sólo fueron concluidas cuando

\footnotetext{
${ }^{74}$ Layna Serrano, Francisco: Historia de Guadalajara y sus Mendozas en los siglos XV y XVI, t. II, Madrid, 1942, pp. 218-219.

${ }^{75}$ Inserto en AHN, Osuna, leg. 1730-2; también en leg. 1724-13(11).

76 1470, septiembre 28, Belmonte. Los marqueses de Villena ordenan a sus vasallos de las villas del Infantado que reciban por señor al rey de Castilla. Inserto en AHN, Osuna, leg. 1727-14(15). Hay un traslado del siglo XVIII en el leg. 1724-17.

${ }^{77}$ 1470, octubre 8, Madrid. Enrique IV trueca con Juana de Luna la ciudad de Alcaraz por las villas del Infantado de Huete. AHN, Osuna, leg. 1730-2.
} 
todas las restantes condiciones expresadas en el documento se hallaban ya cerradas. Este hecho explica las vacilaciones que pueden observarse en algunos cronistas que se hacen eco de la operación: así por ejemplo, cabe suponer que durante la negociación se planteó como eventual equivalencia alternativa la entrega a los marqueses de Villena de las villas de Requena y otras, como recoge Barrantes Maldonado ${ }^{78}$, si bien al fin, como hemos visto, fue la ciudad de Alcaraz la cedida por el monarca a cambio de las villas del Infantado.

Una vez llevada a buen término la primera parte de la operación, y contando el rey con el señorío de las villas del Infantado, procedió a cedérselo a Diego Hurtado de Mendoza, segundo marqués de Santillana, padre de Íñigo López de Mendoza, como consta por el solemne privilegio de la donación, expedido el 25 de octubre del mismo año ${ }^{79}$, así como por una orden del mismo día para que los oficiales de la corona entregaran la posesión de las villas a los representantes del Mendoza ${ }^{80}$. Tal como consta en este último documento, en el señorío se entendían incluidas las tercias reales, tal y como las habían disfrutado Juan de Luna y su heredera la marquesa de Villena. Para que no subsistiera duda alguna sobre esta transmisión y sus plenos efectos, el 27 de octubre se exigió a Juana de Luna y a su esposo Diego López Pacheco que prestaran juramento de respetar los términos de la permuta hecha con el rey por la ciudad de Alcaraz, y en el mismo día también el padre de este último, Juan Pacheco, maestre de Santiago, juró respetar dicha permuta y la pacífica posesión de las villas del Infantado por parte del segundo marqués de Santillana ${ }^{81}$.

De esta forma las villas del Infantado pasaron a integrar el estado señorial principal de los Mendoza, como núcleo generador del título ducal de ese nombre que los Reyes Católicos concederían al segundo marqués de Santillana en $1475^{82}$. En esta transmisión del señorío a los Mendoza actúa, como hemos señalado, un apreciable elemento de continuidad familiar que se materializa en el momento en que, a la muerte del primer duque, acaecida a comienzos de 1479, el señorío pasó a las manos del tercer marqués de Santillana y segundo duque del Infantado, Íñigo López de Mendoza, casado con María de Luna, hija del condestable. En adelante, el señorío

${ }^{78}$ Cfr. un eco de esta cuestión en García López, Relaciones topográf cas, p. 164.

79 1470, octubre 25, Madrid. Enrique IV dona las villas del Infantado a Diego Hurtado de Mendoza, marqués de Santillana. AHN, Osuna, leg. 1726-10. Es traslado de 1651, julio 4, Guadalajara. Hay copia en RAH, Col. Salazar, M-13, fols. 91-93v (no. de inventario: 48352).

${ }_{80} 1470$, octubre 25, Madrid. Enrique IV manda al repostero Juan de Valladolid, que tenía por la corona las villas del Infantado, que las entregue a Diego Hurtado de Mendoza, marqués de Santillana. AHN, Osuna, leg. 1724-13(12). Es traslado del siglo XVIII.

${ }^{81} 1470$, octubre 27, Belmonte. Juana de Luna y su marido el marqués de Villena juran cumplir la permuta concertada con el rey Enrique IV de sus villas de Alcocer, Salmerón y Valdeolivas, por la ciudad de Alcaraz. AHN, Osuna, leg. 1730-3(2). Hay copia en RAH, Col. Salazar, M-10, fols. 61v-62 (no. de inventario: 47784). 1470, octubre 27, Madrid. Juan Pacheco, padre de Diego López Pacheco, marqués de Villena, jura acatar y respetar la posesión por parte del marqués de Santillana de las villas del Infantado, que fueron de la esposa de su hijo. AHN, Osuna, leg. 1730-3(1).

${ }^{82}$ AHN, Osuna, leg. 1872-1 (traslado publicado por Layna Serrano, Guadalajara y sus Mendozas, t. II, pp. 475-477); el original se encuentra en el Archivo Ducal del Infantado; noticias sobre la concesión de este título en el MARqués del SAltillo: Historia nobiliaria española (contribución a su estudio), t. I, Madrid, 1951 (=1936), p. 161. 
de las villas del Infantado de Huete quedaría vinculado a los destinos del principal mayorazgo de los Mendoza, y su transmisión hereditaria en el tronco y colaterales de esta familia quedará asegurada a lo largo de toda la Edad Moderna.

\section{CONCLUSIONES}

La transmisión del señorío de las villas del Infantado de Huete durante la etapa Trastámara aparece como un proceso histórico que involucra la suerte de varios de los más destacados linajes de la nobleza bajomedieval castellana. En particular, el hecho de que el señorío cambie de manos con cierta frecuencia, y no siempre en las condiciones más previsibles (como la prisión de Alfonso de Aragón o la falta de herederos de María de Albornoz), podría sugerir, en una primera impresión, una imagen quebradiza o azarosa de esta trayectoria que va desde Alfonso de Aragón hasta los Mendoza, pasando por los Albornoz y los Luna. Y sin embargo, como hemos visto, virtualmente en todo el proceso de transmisión del señorío actúan apreciables elementos de continuidad familiar, como una suerte de líneas de fuerza que orientan el proceso y es fácil reconocer en el cuadro adjunto.

Por ramas más o menos laterales, lo cierto es que los actores principales del proceso resumido en nuestro estudio quedan enlazados y emparentados. Don Alfonso de Aragón era nieto de Jaime II de Aragón, como también lo era Juana Manuel, consorte de Enrique II de Castilla, quien, amén de actuar en ello como rey, pudo entenderse que también actuaba como jefe informal o moral del linaje manuelino al disponer del marquesado de Villena y la tierra que había sido del célebre don Juan Manuel; y fue precisamente usando de esta legitimación familiar manuelina que Enrique II otorgó el marquesado de Villena y el señorío de las villas del Infantado de Huete a don Alfonso de Aragón. Cuando, preso en Nájera, el nuevo señor del Infantado se vio obligado a desprenderse de estos lugares a fin de pagar el rescate, el comprador que halló no se sentía ajeno a esos mismos intereses familiares por los lugares que en su día habían sido de don Juan Manuel: en efecto, el comprador micer Gómez García de Albornoz también estaba emparentado con el linaje manuelino a través de su esposa Constanza Manuel. En cuanto a la nieta de este micer Gómez, María de Albornoz, casó a su vez con don Enrique, llamado "de Villena", quien estaba emparentado, por parte de padre, con Alfonso de Aragón (abuelo suyo), y por parte de madre, con Juana Manuel (abuela también), la consorte del primer Trastámara. Sin embargo, como hemos señalado, dicho estrechamiento de vínculos familiares cada vez mejor entrecruzados entre ramas íntimamente relacionadas con la historia de las villas del Infantado no tuvo en este punto mayores consecuencias, debido a la falta de descendencia del matrimonio entre María de Albornoz y Enrique "de Villena". En cuanto a la relación de María de Albornoz con los Luna y la posterior transmisión del señorío del Infantado a los Mendoza, es cuestión perfectamente clara, y a la que nos acabamos de referir en la sección anterior.

De todo lo cual se sigue, como se ilustra en el referido cuadro adjunto, que a lo largo del periodo estudiado, en la transmisión del señorío de las villas del Infantado operaron ciertos elementos significativos de continuidad familiar que ayudan a comprender como decisiones plenas de sentido familiar tanto ciertas alianzas ma- 
trimoniales como algunas intervenciones regias que tuvieron consecuencias en el referido proceso.

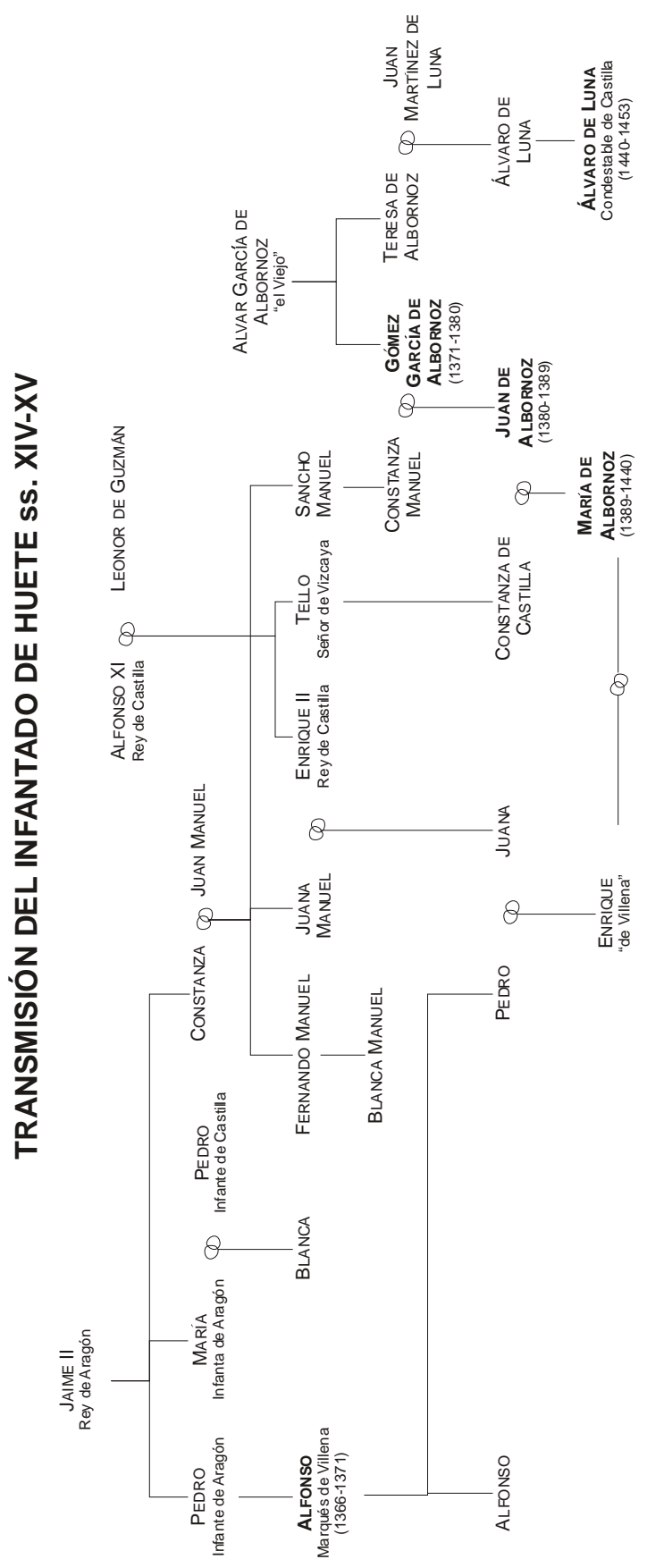

